\title{
Bokrecension: The Two Cultures with Introduction by Stefan Collini
}

\author{
Ulla Riis* \\ Uppsala universitet
}

\author{
The Two Cultures with Introduction by Stefan Collini, av C. P. Snow. Cambridge \\ University Press, 2018, I8I sidor, ISBN 978-I-I07-606I4-2
}

För den som är intresserad av vetenskapssociologi och vetenskapsfilosofi är Charles Percy Snows (1905-80) metafor "de två kulturerna" välkänd. Uttrycket presenterades i en föreläsning i Cambridge, The Rede Lecture, år 1959: The Two Cultures and the Scientific Revolution. ${ }^{1}$ Texten trycktes samma år och vann snabbt uppmärksamhet i brittiska intellektuella kretsar. Kritiken var intensiv, ofta häftig och i åtminstone ett fall ursinnig och obehärskad. ${ }^{2}$

Redan 1962 kom den elfte utgåvan av texten och inför en omtryckning 1964 skrev Snow en tillbakablick på sin text och en kommentar till sina kritiker: The Two Cultures: A Second Look. I min hand håller jag den tjugoandra utgåvan (2018) och i bokhyllan har jag ett exemplar av den sextonde från 1974. Det har varit intressant att läsa om texten och det har varit särskilt givande att ta del av den fylliga introduktion till Snows text som litteraturvetaren Stefan Collini gjorde inför den artonde utgåvan år I993. ${ }^{3}$

Föreläsningen hade två budskap varav endast det första idag förknippas med Snow - att den akademiska kunskapen organiseras och produceras inom specialiserade sfärer skilda från varandra. C. P. Snows andra budskap, och hans egentliga ärende, handlade om klyftan mellan rika och fattiga nationer och människor. Det är rika länders skyldighet att hjälpa de fattiga, hävdar han, och biståndet ska komma genom forskning, genom tillämpad naturvetenskap, teknik och ingenjörsarbete och genom industrialisering. Samt genom utbildning, mer om det strax. Skyldigheten är moralisk och omöjlig att undvika när man en gång blivit den varse:

1 Föreläsningen hölls i maj 1959. Den hade en förhistoria i en artikel tre år tidigare, även den med titeln The Two Cultures (New Statesman, October 1956).

2 Kritiken kom framför allt från de litterära kretsar som värjde sig mot att beskrivas som ointresserade av förändring och "anxious to restrict both art and thought to the existential moment" (s. 5) och att kallas "natural luddites" (s. 22). Litteraturvetaren och-kritikern F. R. Leavis utmärkte sig genom att vara inte bara mycket kritisk mot innehållet i Snows föreläsning utan även mot Snow som författare och samhällsdebattör. Flera andra samtida smakdomare instämde i Leavis kritik men var starkt negativa till dennes obehärskade personangrepp på Snow. Delar av denna debatt i debatten återges av Stefan Collini och nämns även av Snow själv i $A$ Second Look.

3 Collini är idag professor emeritus i engelsk litteratur och idéhistoria vid University of Cambridge.

*Författarkontakt: ulla.riis@edu.uu.se

Artiklar och reflektioner är kollegialt granskade. Övriga bidragstyper granskas av redaktionen. Se https://hogreutbildning.se ISSN 2000-7558 (C)2019 Ulla Riis. This is an Open Access article distributed under the terms of the Creative Commons Attribution-NonCommercial 4.0 International License (https://creativecommons.org/licenses/by-nc/4.0/), allowing third parties to share their work (copy, distribute, transmit) and to adapt it, under the condition that the authors are given credit, that the work is not used for commercial purposes, and that in the event of reuse or distribution, the terms of this license are made clear

Citation: Ulla Riis (2019) "Bokrecension: The Two Cultures with Introduction by Stefan Collini», Högre utbildning, 9(2), 60-64. https://doi. org/10.23865/hu.v9.1984 
"We cannot avoid the realisation that applied science has made it possible to remove unnecessary suffering from a billion individual human lives /... / All this we know how to do. It does not require one additional scientific discovery, though new scientific discoveries must help us" (s. 78).

I sin tillbakablick säger Snow att han från början hade tänkt kalla sin föreläsning "'The Rich and the Poor', and I rather wish that I hadn't changed my mind" (s. 79). Jag både håller med och vill protestera. Uppgiften att förbättra världen - svälten och sjukdomarna, miljön och klimatet - är fortfarande vår tids främsta utmaning och tänk om det budskapet hade kunnat få samma spridning som budskapet om de två kulturerna!

Tillbaka till de två kulturerna: Naturvetare (Scientists) och humanister (Snow talar inte om humanister utan om "literary intellectuals" 4 ) har stora svårigheter att kommunicera med varandra, menade Snow, på grund av att de har olika språk, olika syn på kunskap och kunskapens tillämpning, då de ofta helt enkelt inte förstår varandra och till och med föraktar varandras kunskapsanspråk. Den som läst Snows föreläsning minns säkert anekdoten om den akademiska middagsbjudningen i Cambridge. En gäst, en kyrkohistoriker, försökte konversera några bordsgrannar utan framgång och blev mer och mer förtvivlad då hans värd bröt in för att lugna honom: "Oh, those are mathematicians! We never talk to them" (s. 3).

Snow hävdar att inte bara det intellektuella livet i västerländska samhällen har glidit isär och bildat två poler utan att detta även har kommit att karaktärisera "our practical life" (s. 3). Med "praktisk" syftar han nog främst på akademiskt utbildade yrkesutövare. Hur människor i allmänhet resonerade diskuterade han knappast. Hans utgångspunkt är existentiell: "Each of us is solitary: each of us dies alone", säger Snow. Han fortsätter med att konstatera att den som är humanistiskt bildad tar fasta på det faktum att "the individual condition of each of us is tragic" (s. 6) och lutar mot fatalism, medan naturvetaren förmår hålla isär de individuella villkoren och de sociala. Tack vare förmågan (och/eller viljan) att göra denna distinktion kan naturvetaren se möjligheterna att förbättra världen och tillvaron i stort. Där "humanisten" är konservativ och tillbakablickande är naturvetaren optimistisk, framtidsorienterad och förändringsinriktad.

I föreläsningen knöt Snow samman de två delarna: Eftersom stora delar av jordens befolkning svälter, lider under sjukdomar och dör i förtid så måste de mera lyckligt lottade mobilisera sin kunskap för att delta i lösandet av detta gigantiska sociala armod. Men detta förutsätter att kunskapens olika delar bringas samman för att bli relevant. Klyftan mellan "de två kulturerna" hindrar att detta sker. Snow går här vidare till en kritisk granskning av det brittiska utbildningssystemet med dess tidiga differentiering i ungdomsskolan och specialisering i den högre utbildningen och hävdar att de två "kulturerna" traderas främst på detta sätt. England är extremt i detta avseende menar han och han pekar ut både det nordamerikanska och det sovjetiska utbildningssystemet som modernare och mera ändamålsenligt för att möta samtidens problem. Han nämner även Sverige som exempel på en nation som har förstått att ta tillvara vetenskapliga rön i samhällsbygget.

En föreläsning med rubriken The Rich and the Poor skulle nästan säkert inte ha påverkat tusentals debatter och hundratusentals akademikers sätt att tänka och därför är det angeläget att påminna om Snows huvudbudskap när vi talar om "de två kulturerna".

4 Snow avsåg inte endast det vi idag skulle kalla litteraturvetare utan snarare författare och litteraturkritiker, vilka normalt också var akademiker eller akademiskt utbildade. 


\section{STEFAN COLLINIS KOMMENTAR I993 TILL SNOWS FÖRELÄSNING OCH TILL SPRIDNINGEN AV IDÉN OM DE TVÅ KULTURERNA}

Men bör vi alls tala om "de två kulturerna" idag? Snow har, som sagt, inte saknat sina kritiker genom åren. Stefan Collinis introduktion till Snows text är ett slags historik och en resonerande kritik efter ett tredjedels sekel med Snows tankebygge. Collinis essä ligger idag ett färdedels sekel bakåt i tiden, men känns aktuell. Mer aktuell än hur Snows essä verkar ha framstått för Collini.

Collini låter oss veta att idén om två kulturer inte var unik för Snow utan att den hade formulerats ett antal gånger under I80o-talet, bland annat av författaren H. G. Wells (I866-I946), som Snow hade tagit intryck av. Redan under 1930-talet hade Snow själv diskuterat motsättningarna i Cambridge mellan "litteraturvetare" och naturvetare. Formuleringen "The Two Cultures" lade han fram i en kort artikel 1956.

Eftervärlden har återkommande ställt frågan om det är rimligt att tala om två kulturer. För det första är det tveksamt om 1950-talets "literary intellectuals" i England ens då kunde sägas representera humaniora i hela dess bredd. ${ }^{6}$ För det andra är det oklart om Snow ser skillnaden mellan naturvetare och teknikvetare och ingenjörer. För det tredje saknas samhällsvetenskapen i Snows problembild. Och för det fjärde, och femte, och ... Listan över förslag på antal kan göras lång och är knappast meningsfull. Collini tycker sig se att Snow själv var fångad av sin "Big Idea" om en polarisering och att, allteftersom Snow blev mera känd, "the idea tended to get bigger, the facts fewer, and the prose more forceful" (s. xxix). En sådan utveckling kan vi känna igen i populärvetenskapen via media, där förenkling, schematisering och polarisering ligger nära till hands, där tid och spaltutrymme är knappa och där publiken vill slippa akademikerns" det beror på, och å ena sidan och å andra sidan”.

I en fortsättning på diskussionen om antalet kulturer diskuterar Collini den mycket kraftiga expansionen av universitetsforskningen (och utbildningen) sedan Snows dagar. Detta har inneburit en fortgående differentiering av vetenskapen och en betydande grad av specialisering. Dessutom har ett antal problemområden kunnat etablera sig som nya forskningsområden eller discipliner, Collini ger som exempel feministiska studier och "naturvetenskap och litteratur" (science and literature). Han förhåller sig litet avvaktande till de många "inter- or bi-disciplinary" försöken och deras chanser att lyckas, "but the very attempt may have helped to lessen the gulf of incomprehension implied in 'the two cultures' thesis" (s. liii). Idag kan vi konstatera att de tvärvetenskapliga organisationerna och de mångvetenskapliga ambitionerna har varit många sedan Collini publicerade sin essä. Några av dem har varit dagsländor, en del har överlevt ett par projektomgångar och inte så få har kunnat etablera sig och mött erkännande från mera traditionella delar av akademin. Men framför allt har det skett stora förändringar,

5 Emma Eldelin har granskat fenomenet "de två kulturerna" i sin avhandling från Tema vid Linköpings universitet: "De två kulturerna" flyttar hemifràn: C. P. Snows begrepp i svensk idédebatt 1959-2005. Stockholm: Carlsson, 2006.

6 Snow utgick här ifrån sina egna erfarenheter. Han hade en avbruten forskarkarriär inom kemin bakom sig och ett skäl till att han övergav den var för att han ville etablera sig som skönlitterär författare. Flera av hans romaner behandlar akademiska frågor på sätt som är både roande och moraliskt relevant, bland dem Rektorsvalet (The masters, 1951), De nya männen (The new men, 1954, handlar om atombombsutveckling och människorna/specialisterna bakom den), Affären (The affair, 1959, bland annat om forskningsfusk) och Maktens korridorer (Corridors of power, 1964, diskuterar relationen mellan vetenskap och samhälle). 
teoretiskt och metodiskt, inom de allra flesta discipliner, oavsett om de räknar sin uppkomst decennier eller århundranden tillbaka.

Collini ägnar specialiseringen särskild uppmärksamhet. Den är en oundviklig konsekvens av mänsklig intellektuell utveckling, konstaterar han, och framhåller värdet av att vårt kunnande och våra tillämpningsmöjligheter ständigt förfinas och avkastar, exempelvis nya mediciner eller effektivare bensinmotorer (mina exempel). Det är inte heller så, enligt Collini, att idealet är människor som har förvärvat en gemensam kärna av bildning. Han efterlyser i stället personer som är förmögna till "mutually intelligible exchange of views upon which the effective conduct of a society's affairs depends" (s. lvii). Hinder för detta ser Collini, liksom Snow, i den engelska skolans tidiga specialisering, men också i en tilltagande konkurrens inom vetenskapen och i bristande tid, motivation och förmåga hos många akademiker att samverka med samhället utanför universitetet. En vän till mig och tillika akademisk filosof berättade om hur han deltagit i en middagsdiskussion om en fråga av allmänt intresse - en "exchange of views" - ända tills någon frågande honom om hans yrke. Kommentaren till hans upplysning blev abrupt, "that puts an end to this discussion", sa hans medmänniska och lämnade scenen.

Collini låter Snow få sista ordet och väljer då hans huvudbudskap: "Peace. Food. No more people than the earth can take. That is the cause" (s. lxxi).

\section{DEN FORTGÅENDE SPECIALISERINGEN OCH VETENSKAPENS \\ SAMHÄLLELIGA ANSVAR}

När man ska recensera en text så rik på idéer som den aktuella utgåvan av De två kulturerna står tankar och trängs i skallen. Vad välja att kommentera och värdera? Mitt val blir specialiseringen inom sambällsvetenskapen. Specialiseringen är, som sagt, oundviklig och värdefull. Men den får också allvarliga konsekvenser, till förfång för en god samhällsdebatt och samhälleliga problems lösning av de slag Snow pekade på. Finns det kanske också i specialiseringen, framför allt inom samhällsvetenskap och humaniora, en risk för att undergräva den egna relevansen och samhällets tilltro? Jag begränsar mig nu till just samhällsvetenskapen som jag känner inifrån.

Specialiseringen är alltså immanent i det mänskliga kunskapssökandet. Det är däremot inte en strömning som poststrukturalismen, som i kombination med differentieringen och specialiseringen leder bort från de stora samhällsfrågorna. Visserligen har världen och tillvaron blivit mera svåröverblickbar än den var på 60- och 70-talen (ökade kommunikationer, många och heterogena massmediakanaler, spridning av sociala media), men den forskning som anammat de nya teorierna och metoderna har sannerligen inte gjort särskilt mycket för att granska detta faktum eller för att överbrygga människors vacklande världsbild. Tvärtom. Korroborerade fakta och genomarbetad statistik, som bland annat beslutsfattare behöver, är inget för den poststrukturalist som letar efter ännu en språklig vändning att beskriva eller ytterligare en dekonstruktion att utföra. Samhällsvetenskapen, som borde ha ögonen på just samhällsfrågorna och det politiska handlandet, sviker sin uppgift om den enbart blickar inåt.

Stefan Collini nämner helt kort det han kallar den mikroelektroniska revolutionen och dess stora inverkan på dagligt liv. Vad han däremot inte hunnit bli varse är de effekter som kombinationen av datateknik och teleteknik skulle få för våra kommunikationsmönster. För de (samhälls)vetenskapliga specialisterna har vår tids kommunikationsteknik inneburit kraftigt ökade möjligheter till samarbete, till exempel med specialister inom det egna området - på andra sidan jordklotet. Detta sätt att använda värdefull tid innebär inte sällan (ännu) mindre av kommunikation med kollegorna nationellt eller lokalt, i seminariet eller i fikarummet. 


\section{Ulla Riis}

Informationsutbyte inom specialiseringen konkurrerar rimligen också med tid för samverkan med det omgivande samhället.

Specialiseringen är även nödvändig för att utbildningarna ska kunna ge de studerande de djupa kunskaper de behöver, men i farans riktning ligger risk för specialiseringstänkande redan i grundutbildningen. För vem ska tillhandahålla den kunskapsintegration som Snow efterfrågade för universitetsutbildningens och för samhällsbyggets skull?

Fake news upprör oss som anständiga individer. De förskräcker oss som samhällsvetenskapliga forskare när våra sanningsanspråk ifrågasätts och till och med förlöjligas. Men jag tror inte på detta som enda skäl till att dagens samhällsvetenskap ibland ifrågasätts och ofta får se sin betydelse och relevans minska. Det samhällsvetenskapliga universitetet kan inte räkna med att förbli en röst att räkna med om det inte lär sig kombinera djup insikt med ansvarstagande kringsikt. 